\title{
RECIPE FOR DISASTER How the Dynamic Ingredients of Risk and Exposure Are Changing the Tornado Disaster Landscape
}

\author{
by Walker S. Ashley and Stephen M. Strader
}

The classic mental picture of a tornado dancing across a rural landscape-derived, in part, from the memorable sepia scenes in the film The Wizard of $\mathrm{Oz}$ - is being replaced incremen-

tally by the horrific views of tornadoes devastating communities as the hazard increasingly interacts with amplifying population and development.

$\mathrm{R}$ ecent tornado disasters-including the 2011 Joplin, Missouri, enhanced Fujita scale category 5 (EF5) event, the late April 2011 mid-South outbreak, and 2013 Newcastle-Moore, Oklahoma, EF5-are illustrative of the enormous socioeconomic impact that can occur due to nature's most violent weather hazard. These events affected, to varying degrees, developed landscapes, resulting in over 500 direct fatalities, thousands of injuries, and approximately $\$ 14-16$ billion in direct losses (NCDC 2015; Smith and Matthews 2015). The cases are part of a broader trend found in regional, national, and global hazard loss data, revealing that losses from weather-related disasters, including nonnormalized tornado losses in the United States (Simmons et al. 2013), have been growing due to, principally, societal changes (e.g., inflation, wealth, built environment) (cf. Bouwer 2011; Field et al. 2012; Ashley et al. 2014; Mohleji and Pielke 2014). Recent climate research (cf. Tippett et al. 2015) has revealed an intensification in the year-to-year variability and clustering of tornado counts (Brooks et al. 2014; Elsner et al. 2015), as well as the potential for increasingly frequent and more variable environments supportive of severe convective storms and their hazards due to anthropogenic climate change (Trapp et al. 2007a,b, 2011; Diffenbaugh et al. 2013; Gensini et al. 2014; Gensini and Mote 2014, 2015; Tippett 2014). At the outset, these findings suggest that the trend in tornado disasters, affiliated impacts, and their potential are a combination of changes in both risk and vulnerability landscapes. Yet, because of the complexity of disaster attribution, very little research has examined the interrelationship of disaster drivers in an integrated framework (Huggel et al. 2013), focusing rather on climatological risk or human and physical vulnerability in relative isolation. Moreover, data limitations and (in)accessibility have restricted our capacity to uncover the contributions of both physical and social constituents to tornado disaster constructs and possibilities across both space and time.

\footnotetext{
${ }^{1}$ As with a number of terms in hazard science, the words risk and vulnerability contain multiple conceptions and meanings (Paul 2011). In our assessment, we are using a basic climatological definition of the word risk that simply relates to the probability of a hazard, such as a tornado, occurring in space and time. Exposure is an important component of human and/or system vulnerability, which, itself, also includes elements of sensitivity and adaptive capacity (Morss et al. 2011). Exposure, in our study, is assessed by tallying land use or housing units potentially affected by the tornado hazard.
} 
This investigation characterizes the importance of human and built-environment exposure (as measured by housing units and land use) and its interrelationship with tornado risk (as measured by counts of EF1+ tornadoes and their footprints) over 60 years for a number of tornado hazard geographies. In particular, we uncover differences in exposure, which is an important component and driver of vulnerability, and risk landscapes across tornado-prone regions of the United States, assessing how the dynamic variables of exposure and risk are evolving and interacting to create differences in tornado hazard impact and disaster potential. We examine further regionalization of tornado mortality as prior assessment of these rates at the national level can be misinterpreted to smaller scales since mortality is inherently uneven due to variations in risk and vulnerability across the landscape. We conclude by examining tornado exposure for contemporary high-impact cases to illustrate how national- and regional-scale changes discovered can be manifest at the scale concomitant with the hazard. Ultimately, the study interrogates where, and in what sense, tornado disaster potential has intensified because of an increasing and expanding human-built environment interacting with evolving risk. The research places a spotlight on exposure as an important force behind increasing disaster consequences, providing a foundation for understanding the dynamic nature of exposure and its role in the escalation of disaster impacts.

DATA AND METHODOLOGY. Exposure, in this research, is assessed by tallying the number of housing units [defined as a house, apartment, mobile home, group of rooms, or a single room that is occupied (or if vacant, is intended for occupancy) as a separate living quarter; U.S. Bureau of the Census 2010] and/or land area potentially affected by the tornado hazard. We use finescale $(100 \mathrm{~m})$ residential built-environment data from 1950 to 2010 derived from the Spatially Explicit

AfFiliations: Ashley and StRADER-Meteorology Program, Department of Geography, Northern Illinois University, DeKalb, Illinois CORRESPONDING AUTHOR: Walker S. Ashley, Meteorology Program, Dept. of Geography, Northern Illinois University, Davis Hall, Rm. II8, DeKalb, IL 60II5

E-mail: washley@niu.edu

The abstract for this article can be found in this issue, following the table of contents.

DOI:I0.II75/BAMS-D-I5-00I50.I

A supplement to this article is available online (10.II75/BAMS-D-15-00150.2)

In final form 5 August 2015

(C2016 American Meteorological Society
Regional Growth Model (SERGoM; Theobald 2005). This spatial allocation growth model employs census and road density data to derive the distribution of housing units (HUs), with model accuracy measured using a hindcast technique (cf. Theobald 2005). The SERGoM's primary metric is HU density, which was used to classify each 100-m grid cell into a land-use type (Theobald 2005). HU density is a marker for residential exposure and, moreover, is a suitable metric to employ since $70 \%$ of all tornado deaths (2003-13) occur in residences and because the measure is far more stable on a temporal basis than population.

Tornado counts, fatalities, magnitudes (EF scale), lengths, widths, and other attributes for 1954-2014 were gathered from the Storm Prediction Center (SPC; www.spc.noaa.gov/gis/svrgis). We restricted climatological analysis to EF1+ events since the number of annual EF1+ counts contain a stable linear trend for the period (Fig. 1a; cf. Brooks et al. 2014) and because $\mathrm{EF} 1+$ events have produced nearly all fatalities $(98.7 \%$ for a 60-yr period) and reported damage (Ashley 2007; Simmons and Sutter 2011). By excluding EF0 events, we remove significant inflation created largely by nonmeteorological influences (Verbout et al. 2006; Doswell 2007; Agee and Childs 2014) that affected the trend in these comparatively insignificant events.

Tornado footprints were initially constructed based on the geographical start and end points of each observed event. Because of shifts in tornado width reporting strategies (Brooks 2004; Agee and Childs 2014; Strader et al. 2015a), we used a contemporary portion of the record (1995-2014) to calculate the mean tornado maximum path width for each EF magnitude and assign that mean path width to each tornado based on its EF rating. These two-dimensional footprints are then intersected with the exposure surfaces to determine historical impacts on HUs and land covers. More information about the construction of tornado footprints, potential dataset biases, and the relationship between tornado length, width, and EF magnitude, is available in the online supplement (http://dx.doi.org/I0.II75/BAMS-D-I5-00150.2).

Annual assessments of tornadoes have a tendency to focus on large enumerations - that is, the conterminous U.S. scale-which limits the contextual and spatiotemporal understanding of hazard risk and impacts (Trapp and Brooks 2013). Initially, results herein are provided for two macroscale areas, including the conterminous United States (labeled "US" in the figures) and for the area east of the Continental Divide (CD), which accounts for $93 \%$ of all recorded EF1+ tornadoes in the nation. Subsequently, analyses were constructed for equal-area regions prone to distinctive 


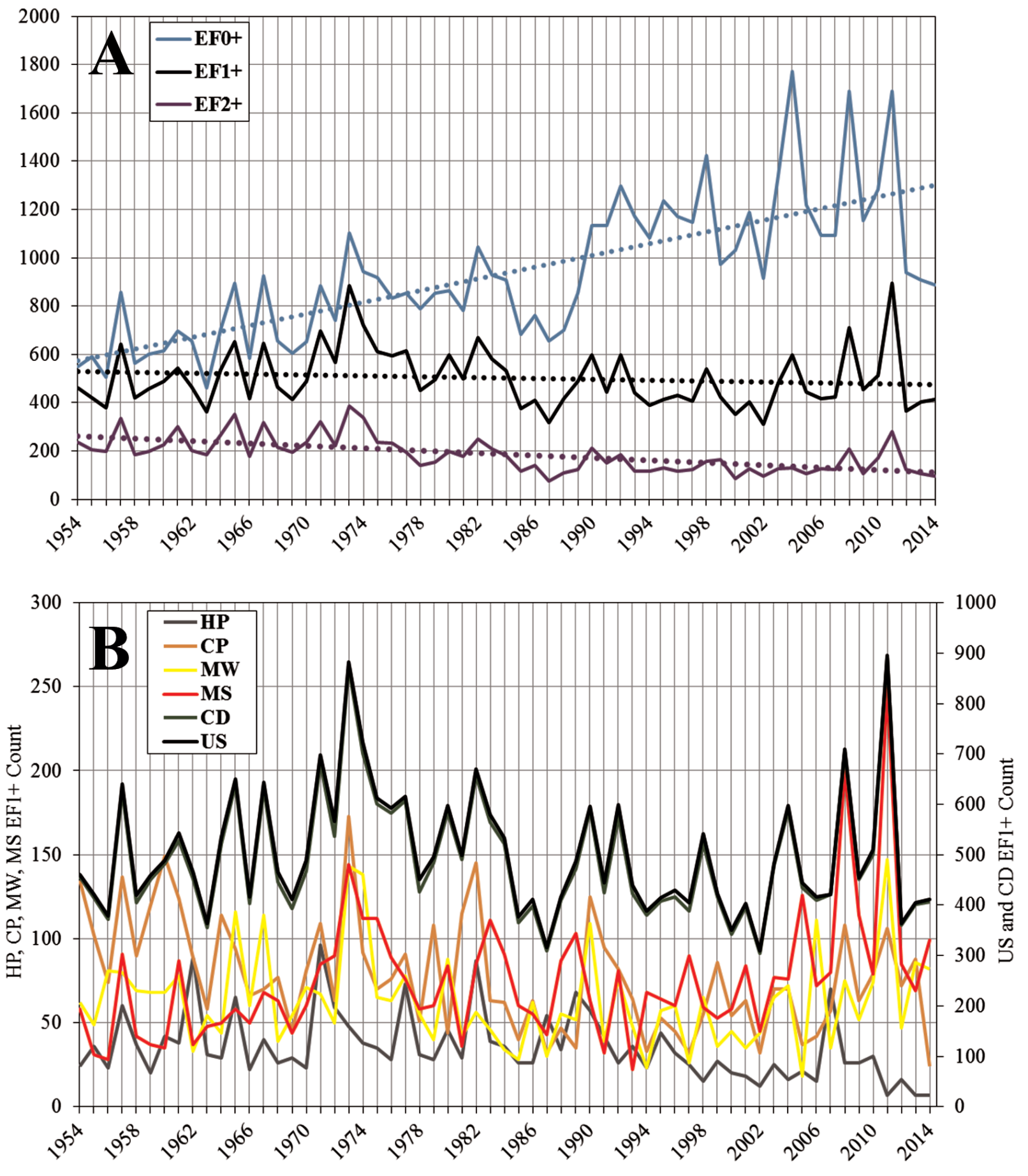

FIG. I. (a) Annual EF0+, EFI+, and EF2+ tornado counts from 1954 to 2014 for the conterminous United States. Linear least squares fits are represented by dashed lines. (b) Annual EFI+ counts for US, CD, HP, CP, MW, and MS regions (cf. Fig. 2 for delineations).

combinations of hazard risk and vulnerability to illustrate how varying rates of these disaster ingredients may contribute to the unevenness of tornado-related impacts across the landscape (Fig. 2). Regions include the high plains (HP) and the central plains $(\mathrm{CP})$, which are areas that intersect what is colloquially known as
Tornado Alley (cf. Brooks et al. 2003; Gagan et al. 2010; Dixon et al. 2011; Marsh and Brooks 2012; Dixon and Mercer 2012), that contain some of the highest mesocyclone supportive environments and tornado frequencies (Smith et al. 2012; Tippett et al. 2015), and that offer comparatively divergent exposure rates; 


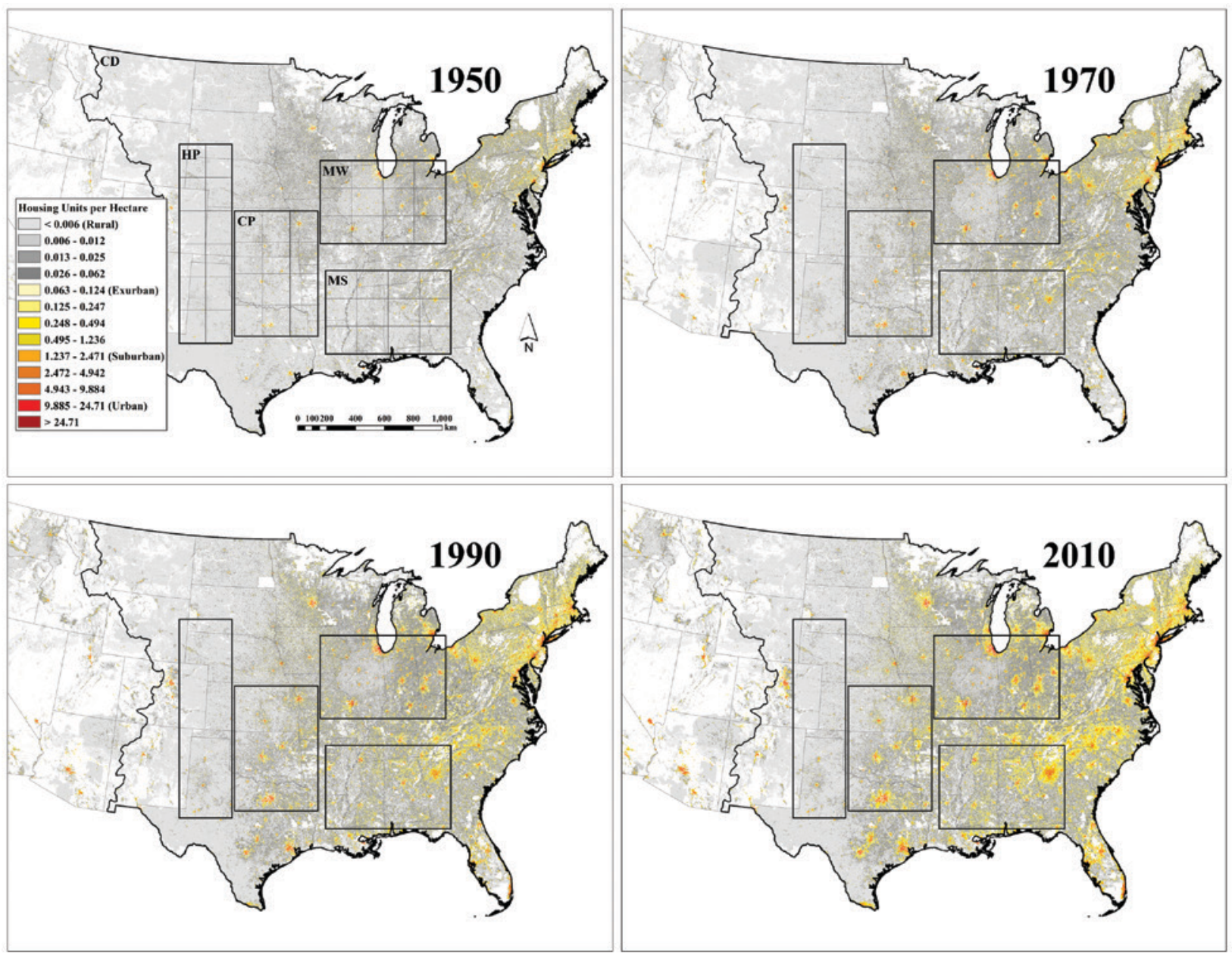

FIG. 2. Total HUs per hectare 1950, 1970, 1990, and 2010, with the CD, HP, CP, MW, and MS regions represented. In the top-left panel, the four regions are subdivided into 12 equal areas for analysis presented in Fig. 9.

the mid-South (MS), an area that has a high risk-and potentially greater risk than the $\mathrm{CP}$ (Coleman and Dixon 2014)-for significant (EF2+) events and the highest frequency of fatalities and killer tornado events (Ashley 2007); and the Midwest (MW), which is an area that contains a mixture of ingredients found in the other regions (Ashley et al. 2008).

RESULTS. Tornado risk. Disasters are a product of society and are caused by extreme events interacting with human, social, and physical vulnerabilities. Thus, at the most basic level, there must be a hazard risk at a location for there to be disaster potential. An extensive body of research has characterized tornado climatology, or risk, in the United States (Abbey and Fujita 1975, 1979; Schaefer et al. 1986; Fujita 1987; Grazulis 1993; Boruff et al. 2003; Brooks et al. 2003; Dixon et al. 2011; Doswell et al. 2012; Widen et al. 2013; Farney and Dixon 2015; among others). We update these prior results, revealing that $\mathrm{EF} 1+$ tornadoes are most frequent in the $\mathrm{CP}$ and MS, with additional elevated risk found throughout the MW and Ohio Valley, as well as east of the Front Range of Colorado (Fig. 3). The United States averages just over 500 (183) EF1+ (EF2+) tornadoes yearly, with $97.8 \%$ (98.4\%) of those events occurring east of the CD. The CP $\left(78 \mathrm{yr}^{-1}\right)$ and MS $\left(75 \mathrm{yr}^{-1}\right)$ have very similar EF1+ frequency risk, while the MW has a slightly lower risk $\left(63 \mathrm{yr}^{-1}\right)$, and the HP $\left(35 \mathrm{yr}^{-1}\right)$ a considerably lower reported relative threat. The true risk in the HP region, and, to an extent, in other domains, may be understated due to the lack of population, leading to decreased reporting frequency (Anderson et al. 2007; Coleman and Dixon 2014), and the dearth of built environment, reducing possible damage indicators for tornado magnitude rating (Doswell and Burgess 1988; Doswell et al. 2009; Strader et al. 2015a), especially early in the record. Regionally, reported EF1+ risk has been shifting, with a decreasing (increasing) trend in EF1+ annual counts in the HP and CP (MS) for the period of record (Fig. 1b). It is difficult to explain what may be causing these shifts in the long-term event frequency, but it 

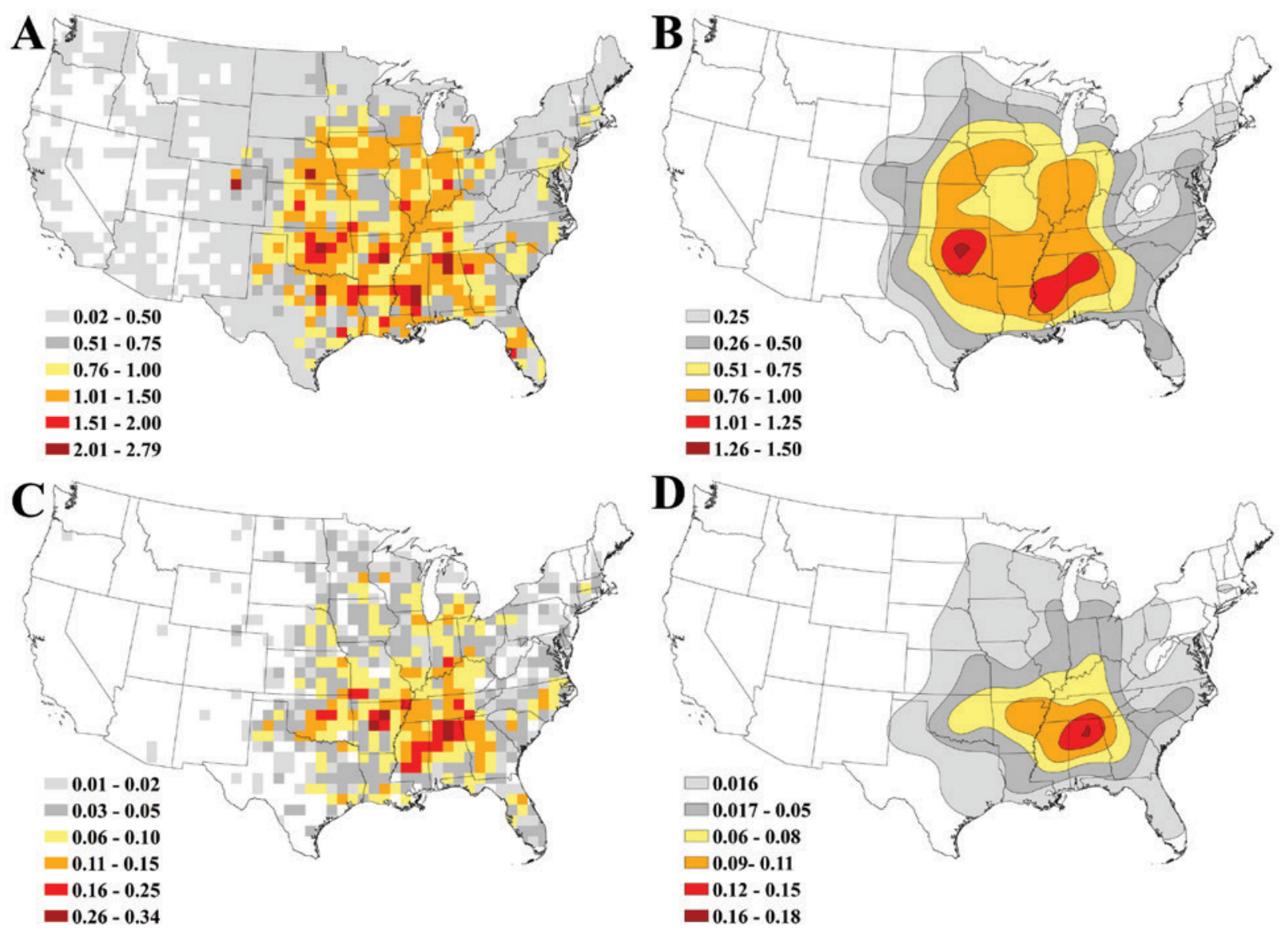

FIG. 3. The number of mean annual (a) EFI+ tornado line segments, or paths; (b) smoothed EFI+ tornado paths; (c) killer EFI+ tornado paths; and (d) smoothed killer EFI+ tornado paths. Path grid intersect counts are calculated on an $80 \mathrm{~km} \times 80 \mathrm{~km}$ grid from 1954 to 2014 and smoothed using a $3 \times 3$ low-pass filter.

may be a combination of meteorological and nonmeteorological effects, such as the relative short period of the observed record, influences of storm chasing, changes in reporting and verification strategies, climatological shifts in environments favorable for tornadoes, and/or the influence of outbreaks (Doswell 2007; Gensini and Ashley 2011; Coleman and Dixon 2014). For instance, the removal of recent outbreak years (2008 and 2011) in the MS promotes a more level regional annual frequency trend. Extreme events, such as those that characterize outbreaks like 27 April 2011, are relatively rare (Shafer and Doswell 2010; Doswell et al. 2012), but they can have a notable influence on fingerprints of risk, especially on regional domains that are relatively small (Coleman and Dixon 2014).

A theoretical tornado footprint [observed length multiplied by the U.S. prescribed mean (1995-2014) maximum width based on EF magnitude] offers another perspective for gauging risk. In a given year, the $\mathrm{MS}$ region has the largest total $\mathrm{EF} 1+$ tornado footprint of the regions examined, or $335 \mathrm{~km}^{2}$. This collective theoretical hazard footprint is nearly $24.3 \%$ larger than the comparatively active CP, $44.2 \%$ larger than the MW, and $124.5 \%$ larger than the HP. On average, the MS (CP) contains $21.3 \%$ (16.7\%) of all EF1+ U.S. tornado footprint area despite containing only $6.4 \%$ of the U.S. land area.

The mean EF1+ event in the CD has an area of nearly $3.16 \mathrm{~km}^{2}$; regionally, these values vary from $4.47 \mathrm{~km}^{2}$ in the MS and $3.38 \mathrm{~km}^{2}$ in the MW and CP to $2.20 \mathrm{~km}^{2}$ in the HP. While the CP has a slightly greater frequency of EF1+ tornadoes than the MS, the footprint of the tornadoes that do occur in the MS are nearly $28 \%$ larger than those that occur in the CP. Thus, it is not the frequency of events that defines risk of a geography; rather, the inherent spatial character of the tornado hazard combined with event frequency determines impact potential (Dixon and Mercer 2012; Coleman and Dixon 2014), which is illustrated when risk is intersected with exposure in forthcoming sections. For instance, tornadoes in the MW (HP) are $23 \%$ (47\%) shorter than those in the MS, while in 
comparison to the correspondingly active $\mathrm{CP}$ region, tornadoes in the MS are nearly $26 \%$ longer than their $\mathrm{CP}$ counterparts. The MS's propensity for cool-season events (Brooks et al. 2003; Tippett et al. 2012) suggests that tornadoes and their parent storms in the region will likely have relatively high forward speeds with a greater probabilistic threat to the landscape compared to the other active regions examined.

Conterminous United States and regional exposure. Most research assessing hazard impacts has not appraised spatiotemporal changes in exposure as an important driver of changes in the disaster landscape (Bouwer 2011). Investigations (e.g., Simmons et al. 2013; Visser et al. 2014; cf. Bouwer 2011) have used coarse normalization schemes to, in theory, remove the effect of societal changes to examine trends in disaster frequency/ magnitude; however, it is these societal changes (measured via exposure, or HUs and land use, in our case) and their influence on disaster potential from the local to regional level, and across time, that we want to understand and measure. Even at the large scale (Fig. 2), it is visually apparent that the United States has undergone a rapid transformation from urban to suburban to exurban development morphologies, leading to a notable spread in developed land and its people at risk to hazards - the expanding bull's-eye effect discussed by Ashley et al. (2014).

Between 1950 and 2010 (Fig. 4), the number of HUs in the United States (CD) increased by 98.2 (79.2) million, or $376.9 \%$ (345.7\%). Most growth in the United States, and in the regions assessed, has been in the exurban and suburban development morphologies, largely at the expense of rural land (Fig. 5). In the United States, the percentage of developable land has decreased from $95.3 \%$ to $78.15 \%$ rural, while

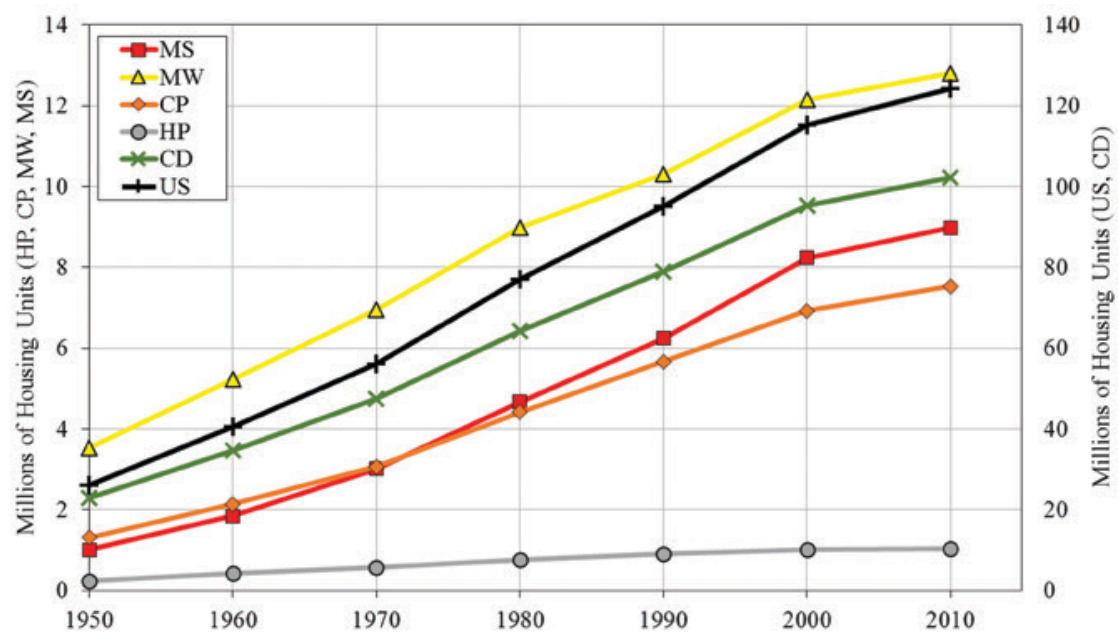

FIG. 4. Total HU counts by region from 1950 to 2010. exurban (suburban) development has increased from $4.08 \%(0.50 \%)$ to $19.17 \%(2.24 \%)$. Though more land proportionally has been converted to low-density exurban development, the greatest absolute changes in HUs and therefore the greatest potential catastrophic impact are in the urban and suburban morphologies. For instance, in the CD region, the number of HUs has increased just over 30 million for both suburban and urban areas over the $60-\mathrm{yr}$ period, whereas exurban development has increased 17.3 million units and rural 1.63 million. The percentage of developable land that is urban and suburban in the CD is only $2.62 \%$, but this percentage area has grown from a base of $0.58 \%$ in 1950 ; indeed, the CD urban footprint has increased more than fivefold during the 60 -yr period. The amplifying potential for tornado disasters and catastrophes is demonstrable when this higher-density development in cities and their suburbs is combined with the explosive growth in exurbia-from $4.25 \%$ of the CD land area in 1950 to $20.48 \%$ in 2010 , concurrent with a nearly fivefold increase in HU. The growth in HU magnitude and its spread across the landscape are critical to understanding exposure and how it manifests itself in disasters. Recent high-end cases discussed in the introduction are illustrative of how development has created a growing tornado problem, which, unfortunately, has not reached full disaster potential.

Of the regions examined, the MW had the greatest change in the number of HUs (+9.3 million) during the 60 -yr period. However, in terms of percent change in HUs (Table 1; Fig. 4), the growth has been the largest in regions most at risk to tornadoes-the MS $(+790.3 \%)$ and $\mathrm{CP}(+472.7 \%)$. These percent changes are far greater than those found in the U.S. and CD domains, spotlighting how these high-risk regions are also exceedingly vulnerable from an exposure perspective, portending increasing disaster potential. Most of the absolute growth in HUs has been in the urban and suburban land uses in these areas, with the number of HUs in urban areas in the MS increasing nearly $2,000 \%$ and in the CP and HP over a $1,000 \%$. Of the four regions, only the MW has had a lower percentage change in total HUs and HUs by developed land-use type compared to the $\mathrm{CD}$ 

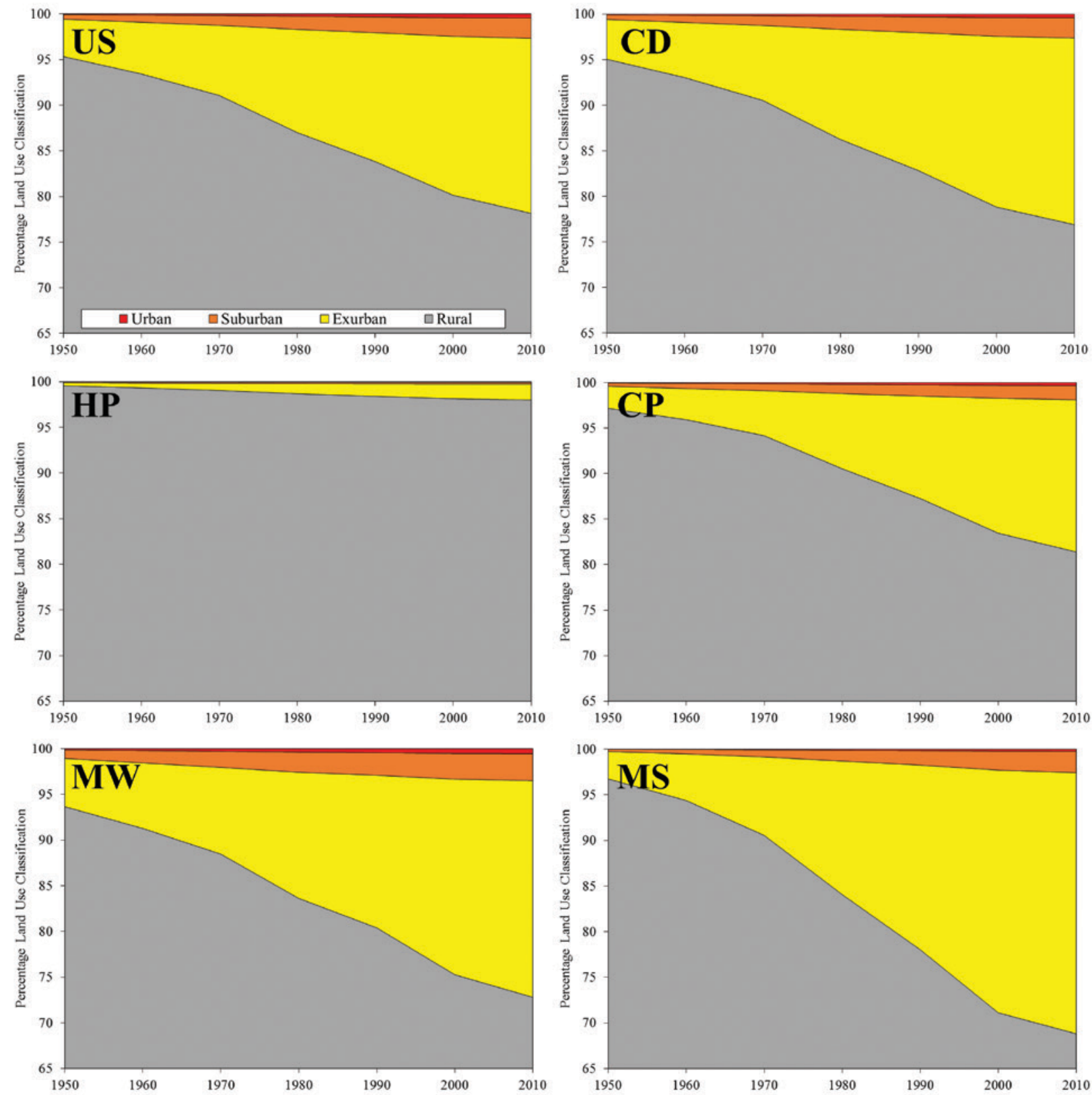

FIG. 5. The percentage land-use classification (urban, suburban, exurban, rural) from 1950 to 2010 by region.

and the United States. This slower percentage change may be due to the extensive agriculture and relatively restrictive zoning and preservation policies found in the MW's Corn Belt (e.g., many ring counties on the edge of the Chicago metropolitan area of Illinois have prime farmland preservation policies that make it economically difficult for leapfrog development), which may act to retard some growth spatially (Brown et al. 2005). Alas, as discussed, compared to the other regions examined, the MW has the highest absolute growth in HUs, with $80 \%$ of that HU increase found in the region's cities and their suburbs.
Regionally, the CP, MW, and MS have lost between $16 \%$ and $28 \%$ of their rural land, with again the most substantial growth found largely in exurban and suburban morphologies. For instance, the MS has witnessed an increase of $1,700 \%$ in area classified as urban during the period, with an increase of over $800 \%$ in suburban and exurban area. The MW comprises the greatest growth in urban and suburban land area and the MS region contains the greatest amount of exurban area growth. The MS already has a very high rural population and $\mathrm{HU}$ density that, when combined with exurban and suburban encroachment, enhances the 


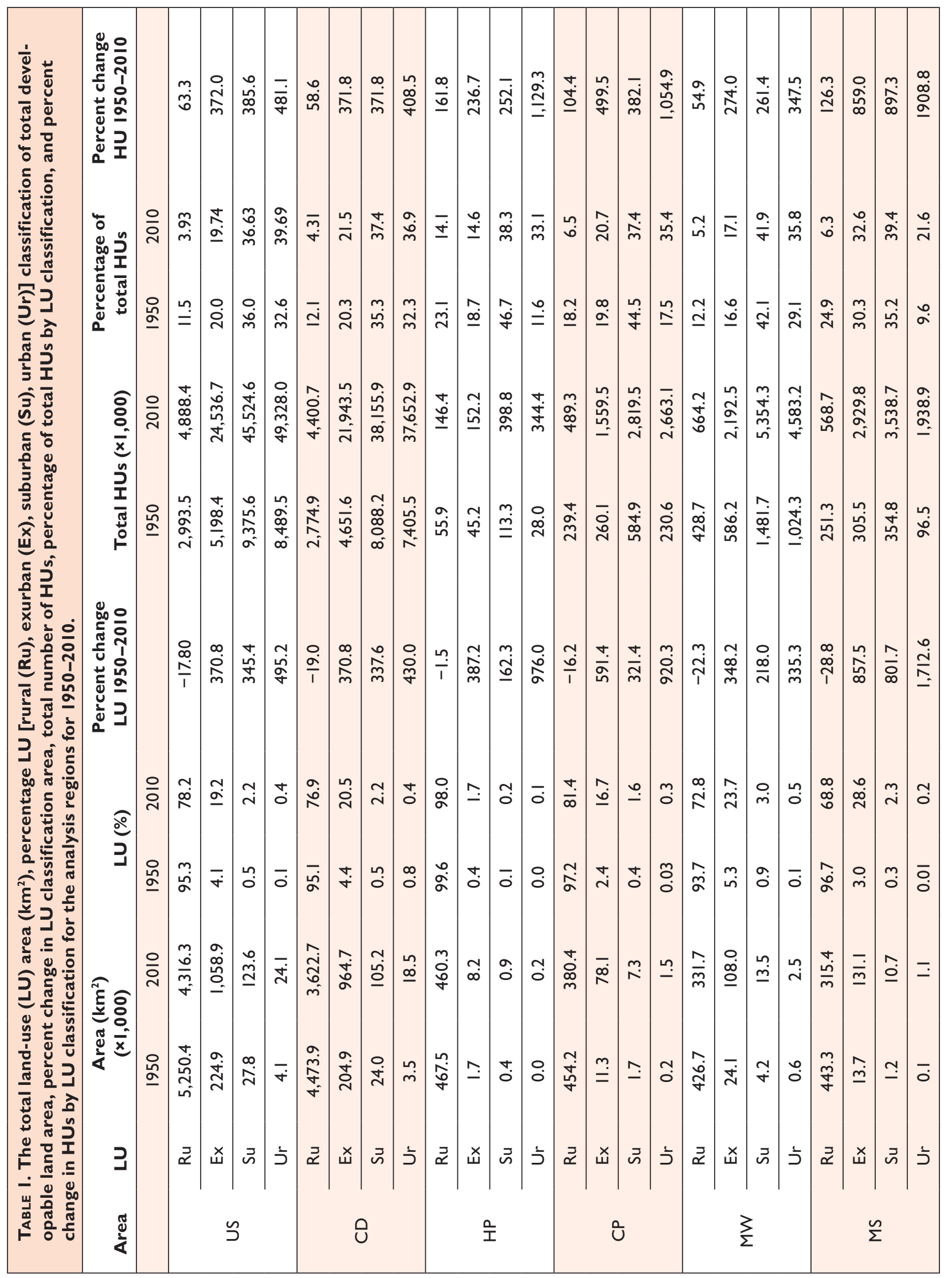


exposure in this region. The $\mathrm{HP}$ and the MW regions have the slowest growth of developed land area, but even this growth is a fourto fivefold increase over the 1950 area.

Interaction of hazard risk with exposure. It is the interaction of a hazard with vulnerability-or, specifically, exposure in our case-that shapes impact. We assess this interaction on the macroscale for the $\mathrm{CD}$ region by placing the theoretical tornado paths [actual geographic path location, length, and prescribed mean (1995-2014) maximum width based on EF magnitude] atop exposure surfaces on an annual basis (Fig. 6). A least squares trend across the total annual number of HUs affected by EF1+ tornadoes reveals a doubling of impacts, from just over 19,000 in the 1950 s to nearly 40,000 in the most recent decade (Fig. 6a): that is, twice as many housing units are being affected by these events in the contemporary period compared to the midpart of the twentieth century. The variability of annual tornado counts and footprint area can affect the trend uncovered; therefore, we use two methods to normalize: first, by area of tornado; and second, by frequency of events. The number of HUs impacted in a given year normalized by total tornado footprint area almost triples (Fig. 6b), from nearly $12 \mathrm{HU}$ per square kilometer to in excess of $29 \mathrm{HU}$ per square kilometer by the most recent period. The mean number of
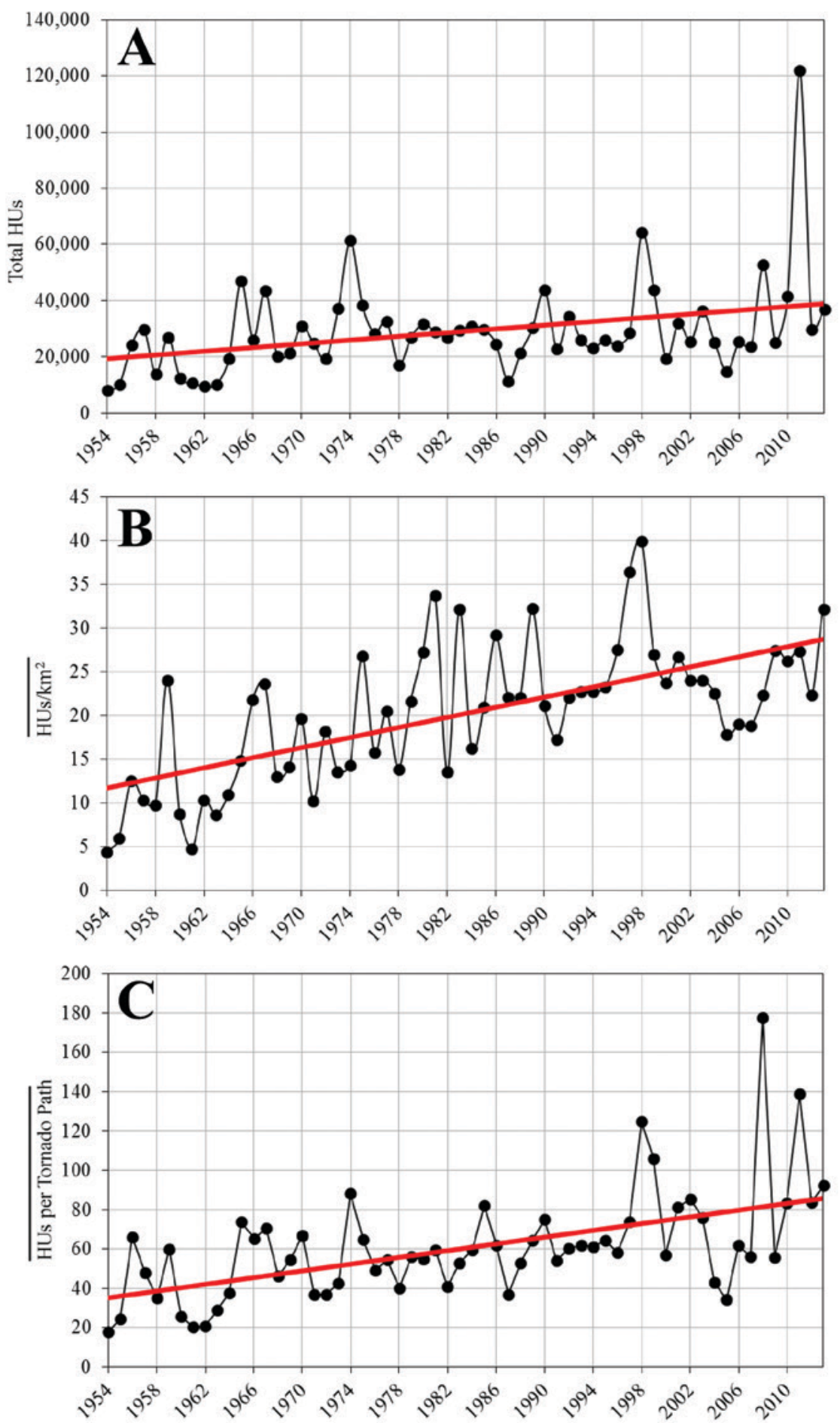

FIG. 6. Annual HU impacts by EFI+ tornado footprint from 1954 to 2014 for the CD region: (a) the total annual number of HUs impacted, (b) the mean annual number of HUs impacted per square kilometer of tornado footprint area, and (c) the mean annual number of HUs impacted per tornado path. Red lines represent linear least squares fits.

HUs per path annually has more than doubled over 60 years. All three trend lines in Fig. 6 have statistically significant increases at the $95 \%$ confidence level. 

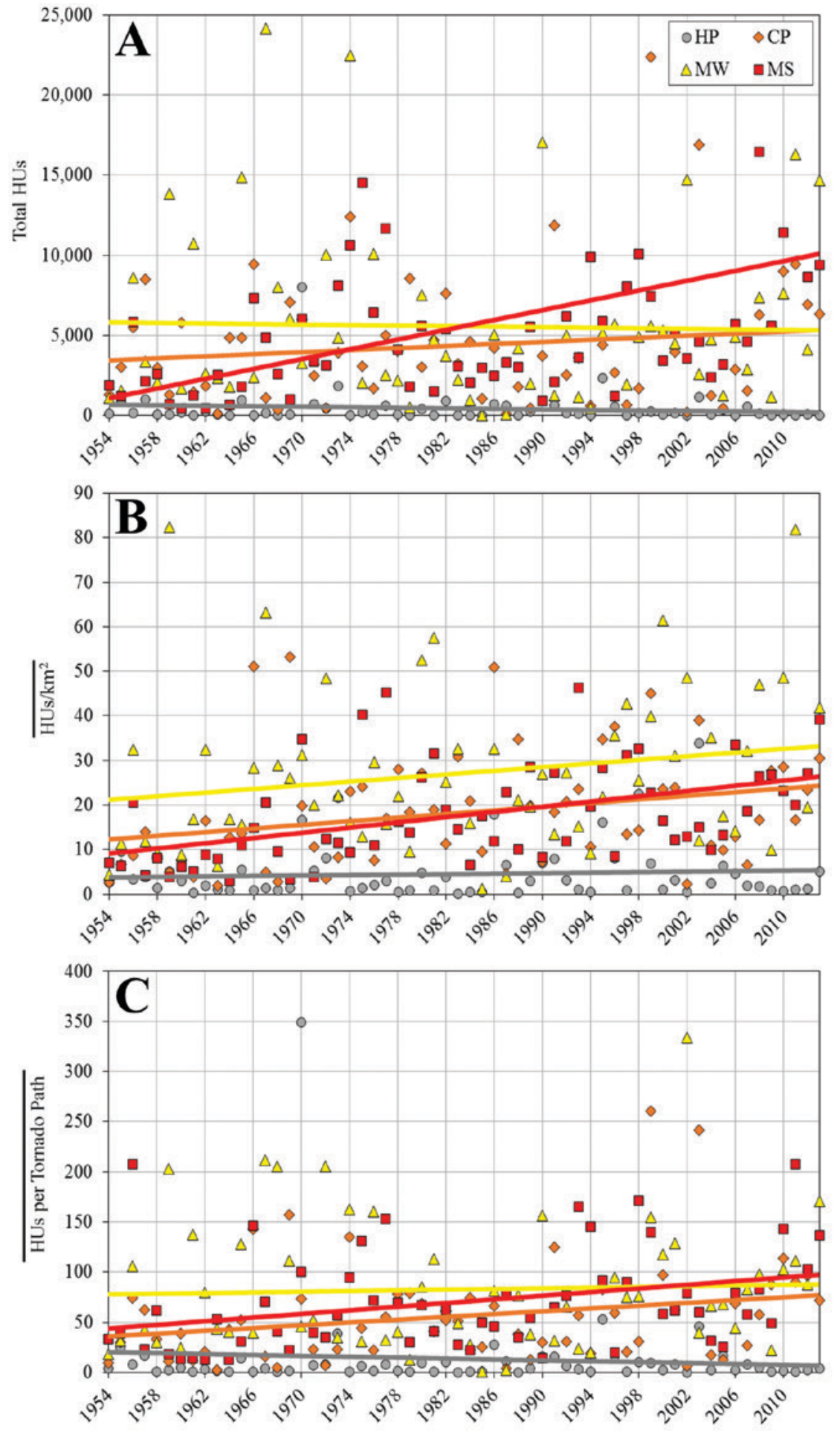

FIG. 7. Annual HU impacts by EFI+ tornado footprints from 1954 to 2014 for the HP, CP, MW, and MS regions: (a) the total annual number of HUs impacted, (b) the mean annual number of HUs impacted per square kilometer of tornado footprint area, and (c) the mean annual number of HUs impacted per tornado path. Linear least squares fits are illustrated with red (MS), orange (CP), yellow (MW), and gray (HP) lines.
Regionally, the MS has experienced the greatest shift in impact for the 60-yr period (Fig. 7). This highrisk (Coleman and Dixon 2014), high-vulnerability region (Ashley 2007) has had a tenfold increase in HUs impacted, a tripling of the number of affected HUs per square kilometer of path, and more than a doubling of the mean number of HUs impacted per tornado. The CP is the only other subregion analyzed that witnessed increases in all categories, with a doubling of the amount of impacted HUs per square kilometer of path and mean number of HUs impacted per tornado. Both the MW and HP regions had decreases in the number of HUs impacted over time; yet, both of these regions had impact growth when HUs affected were normalized by the tornado footprint area, with an increase in the number of HUs impacted per tornado in the MW and a notable decrease in the HP. The relatively small sample size and extreme annual variability found at this regional scale make unmasking trends difficult.

When we combine tornado risk with land-use morphology over time (Fig. 8), we discover that the exurban classification has witnessed the most dramatic growth in cells affected by tornadoes. A similar increase, though not of the same magnitude, is found in the urban and suburban classes, with all of the growth at the expense of rural areas. The only region 


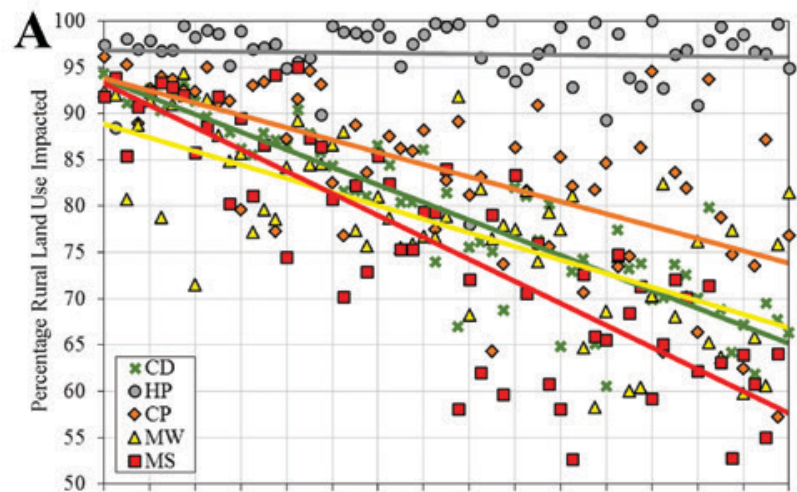

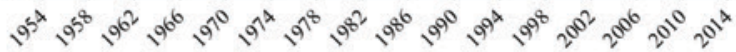

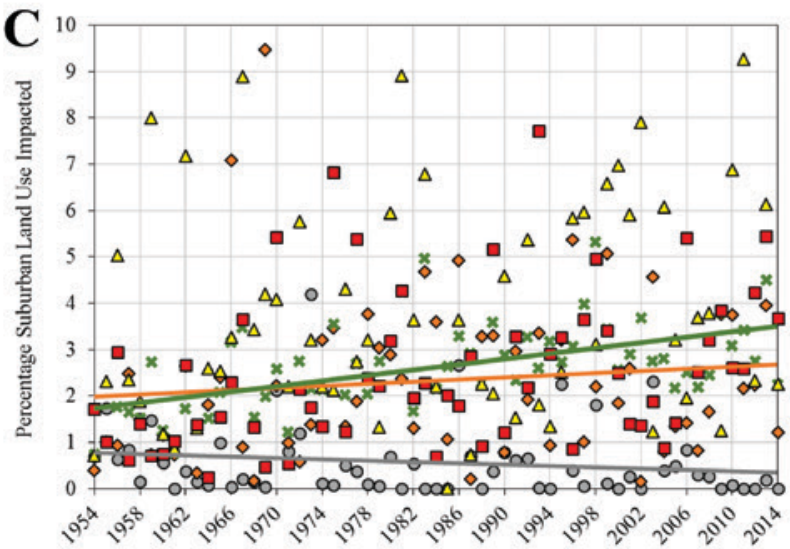

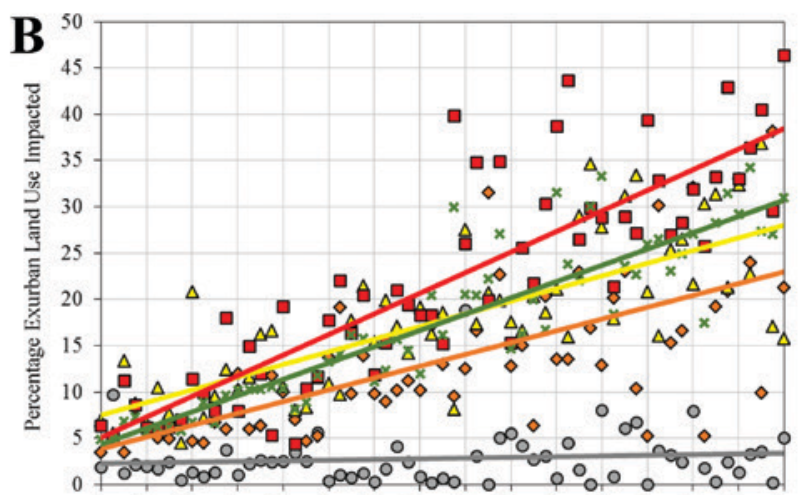
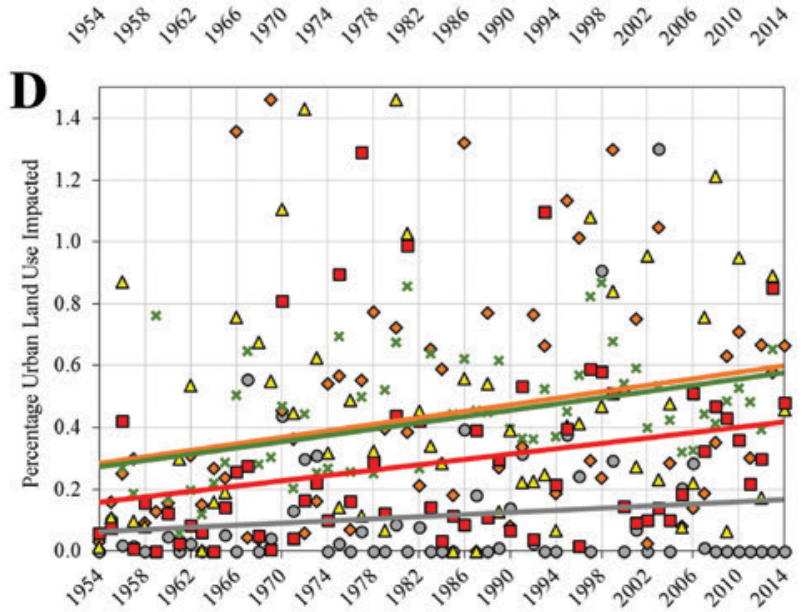

Fig. 8. Annual percentage of land use-classified as (a) rural, (b) exurban, (c) suburban, and (d) urban-that was affected by tornado footprints from 1954 to 2014 for the CD (green), HP (gray), CP (orange), MW (yellow), and MS (red) regions. Linear least squares fits are illustrated and represented by corresponding region colors.

that does not follow this pattern is the HP, which has not observed the development amplification found in the other regions (Fig. 5). Shifting the HP analysis region slightly to the west would modify the results due to the inclusion of the Interstate Highway 25 (I-25) urban corridor, which has experienced strong growth. This analysis confirms that the expanding bull's-eye effect (Ashley et al. 2014) is leading to greater impact on developed landscapes, portending an increase in disaster potential if future development trends are analogous to those found in the contemporary record.

To explorer further risk-exposure interaction, we subdivided each of the four regions into 12 equal areas (Fig. 2), summing the tornado footprint experienced and the amount of HUs in 2010 in each area. This permits a more nuanced analysis within the regions, revealing the influence of cities and how disaster constituents interrelate at smaller scales to shape the regional trends. Subregional areas that fall within the upper-left quadrant of Fig. 9 are more influenced by exposure, while areas that land in the lower-right quadrant are driven more so by tornado risk. As areas shift toward the upper right in the graphic, both risk and exposure increase, signifying greater disaster potential. Broadly, the MS's tornado disaster potential is driven foremost by risk, though cities in the region elevate the exposure and promote more disaster potential relative to the other three regions. Of the four regions, the MW is most influenced by exposure, which is not surprising since the MW has the greatest number of HUs in 2010, with nearly 1.3 million more HUs than the next closest region, the MS. The HP has relatively low exposure and risk, with the risk likely understated as discussed previously. The CP's disaster potential is chiefly directed by risk, thought the Dallas-Fort Worth, Texas, and Kansas City, Missouri, areas intensify overall exposure.

Joint probabilities. A question often asked is "What is the probability that my home or place of business will be impacted by a tornado?" Reinhold and Ellingwood (1982), Schaefer et al. (1986), Fujita (1987), Brooks et al. (2003), Ramsdell et al. (2007), Widen et al. (2013), Coleman and Dixon (2014), and others have assessed tornado probabilities from a climatological perspective, providing an approach 
to answering this question at a variety of scales. The robustness of these probabilities, especially for violent events, is often beset by the small sample size problem (Doswell 2007); however, objective analysis routines on an ever-growing tornado database can provide an effective probabilistic marker for measuring relative risk to life and property from tornadoes. We are interested in furthering this probability analysis for our research, as well as advancing the aforementioned question, by appraising the likelihood that a tornado will affect developed land use in our assessment geographies.

To do this, we calculated a risk-exposure joint probability that an EF1+ tornado path with footprint area (pathlength multiplied by the prescribed EFmagnitude widths discussed previously) traverses a developed grid cell in a given year from 1950 to 2010 (Fig. 10). The risk-exposure joint probability is the proportion of the mean annual total regional EF1+ footprint area multiplied by the proportion of a region's area that is considered developed for that particular decadal time stamp. Effectively, this is the annual chance an EF1+ tornado path is juxtaposed with a developed land-use grid cell.

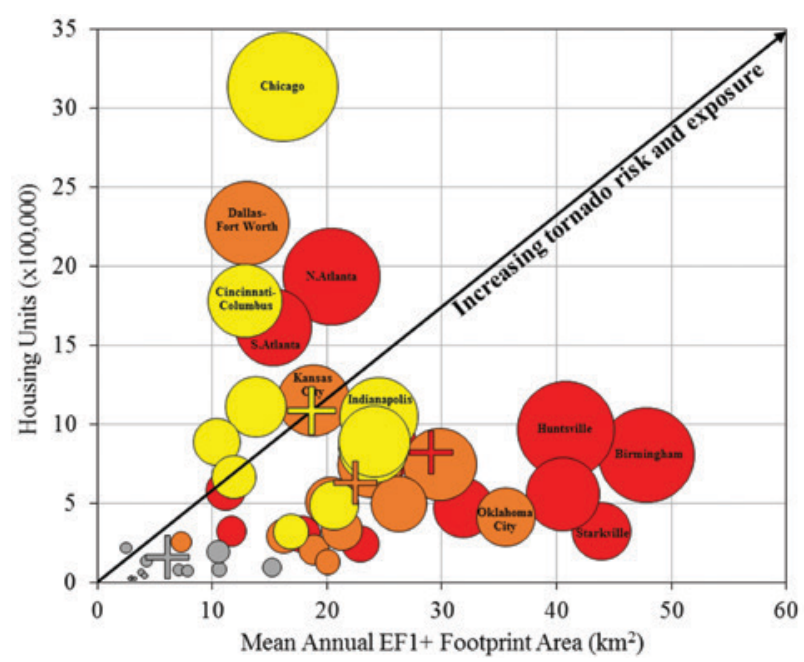

FIG. 9. Relative tornado risk and exposure by HP (gray), CP (orange), MW (yellow), and MS (red) regions. The $y$ axis indicates the total number of HUs in 2010 $(\times 100,000)$ within a regional grid cell $(12$ equal area cells per region), and the $x$ axis represents the mean annual total EFI+ tornado footprint area $\left(\mathrm{km}^{2}\right)$ from 1954 to 2014 within a regional grid cell. Circle size is weighted by the mean annual total EFI+ tornado footprint area from 1954 to 2014 multiplied by the total number of 2010 HUs within a grid cell. Symbols correspond to the gridded mean annual total EFI+ tornado footprint area multiplied by the total number of $2010 \mathrm{HUs}$ within the analysis regions. Major metropolitan areas located within a specific grid cell are labeled.

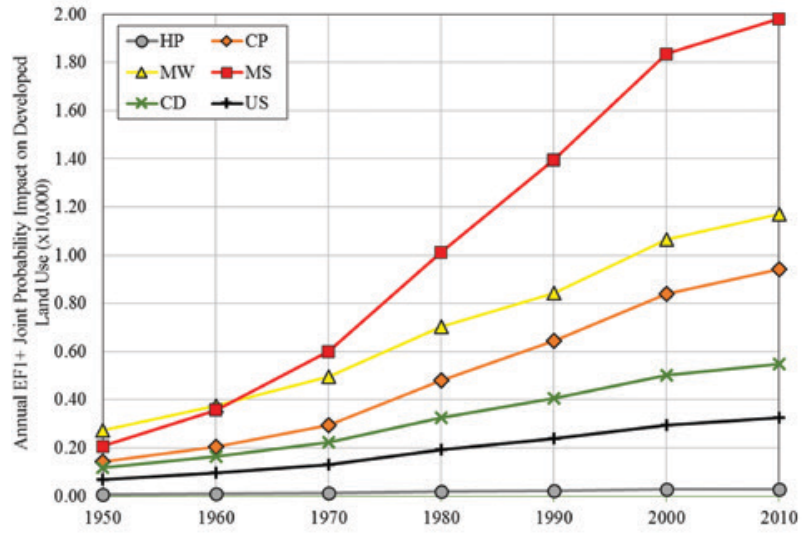

Fig. 10. The annual joint probability $(\times 10,000)$ that an $E F I+$ tornado path is juxtaposed with a developed (urban, suburban, exurban) land-use grid cell by analysis region from 1950 to 2010 .

Results indicate that all regions analyzed have experienced greater than $300 \%$ growth in probabilistic risk-exposure values since 1950 . The MS tornado region had the greatest overall increase in probabilities from 1950 to 2010, swelling to nearly 10 times the 1950 probability. Moreover, the MS region also had the greatest relative joint probability growth compared to all other regions with an increase of nearly $900 \%$ over the last $60 \mathrm{yr}$. This growth in this region's joint probability, or disaster potential, is the product of the development the MS has experienced in the last half century. Similarly, the MW and CP regions have also had large increases in joint probabilities since 1950. While the MW had the second greatest likelihood of tornado impacts on a developed landscape, the $\mathrm{CP}$ had a greater percentage change $-560 \%$ versus $329 \%$-in joint probability values. Although the CP region does not contain as much developed land as the $\mathrm{MW}$, the CP region has had a greater amplification in the possibility of an EF1+ tornado path traversing a developed landscape. The MS, MW, and CP regions all have far greater risk-exposure joint probabilities than that found in the broader U.S. and CD geographies; only the HP, with its limited HU density, has a lower joint probability compared to the United States and the CD.

Tornado mortality. One of the most definitive and unfortunate effects of a hazard interacting with vulnerabilities is human mortality. An assessment of tornado-related mortality can provide a fundamental understanding of how a hazard mixes with physical and human systems; moreover, it can inform measures to reduce future death and injury. Previous research has examined the spatiotemporal distribution of 

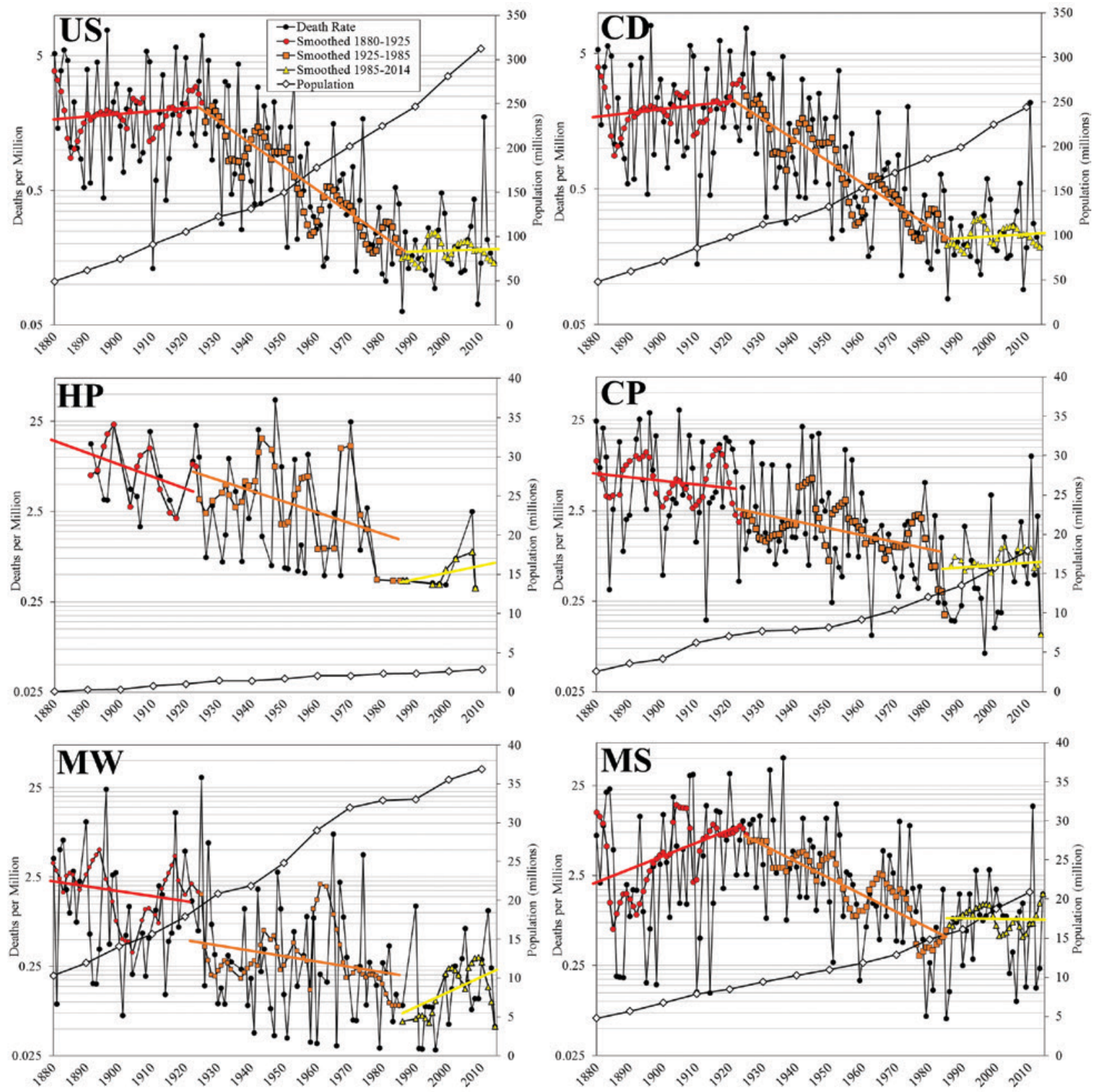

FIG. II. Tornado death rate per million people per year in the analysis regions from 1880 to 2014 . The thin black lines with black circle markers represent the raw tornado death rate; the curved line with red (1880-1925), orange (1925-85), and yellow (1985-2014) markers represents the filtered death rate by a three-point median and five-point running mean (after Brooks and Doswell 2002); and the thick red, orange, and yellow lines represent linear least squares fits to the filtered death rates for the three periods of examination. Black lines with diamond markers are the regional census population in millions from 1880 to 2010 . Fatality data from the SPC and Grazulis (1993). Linear interpolation between decennial censuses was used to estimate population within domains.

tornado fatalities (Ashley 2007; Ashley et al. 2008), but it has had a tendency to examine mortality rates at coarse resolution (Brooks and Doswell 2002; Simmons and Sutter 2011). Death rates obtained at the conterminous scale can be deceptive when presupposed regionally since mortality is inherently uneven due to variations in both risk and vulnerability across the landscape. Our spatial framework provides a method to uncover how these mortality rates may manifest at a smaller scale.

For the better part of the twentieth century, annual U.S. tornado death tolls and mortality rates were in decline (Fig. 11; Brooks and Doswell 2002). As discussed in Doswell et al. (1999) and Brooks 


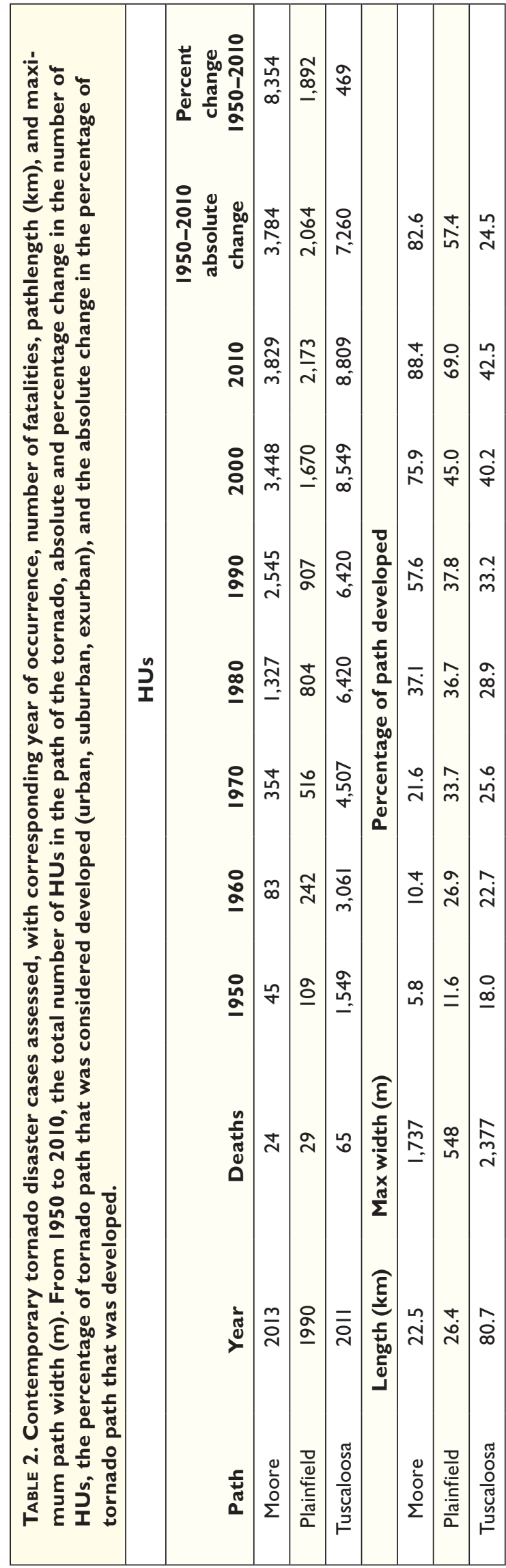

and Doswell (2002), many societal, technical, and scientific factors-the advent of modern forecasting, improved warning dissemination, spotter networks, education of hazard and mitigation strategies, construction, etc.- - have all contributed, in some manner, to the decline. Brooks and Doswell (2002) suggest that the drop may be statistically attributed to the decrease in the number of, what they term, "big years" (e.g., extremely high tornado toll years, such as 1925), as well as the reduction in the number of killer tornadoes per year. The long-term decline in mortality uncovered in prior research has been essentially discontinued, with the annual U.S. death rates holding steady since 1985 at around 0.25 per million. The contemporary rate is still a considerable reduction from the late nineteenth and early twentieth centuries (mean of 2.4 million $^{-1} \mathrm{yr}^{-1}$ from 1880 to 1924 ) and the midtwentieth century ( 1.1 million $^{-1} \mathrm{yr}^{-1}$ from 1925 to 1984), but the stall is unnerving considering the rapid advancement of meteorology, investment in National Weather Service (NWS) modernization, and development of modern communication systems during this period. As proposed in Brooks and Doswell (2002), Ashley (2007), and Hall and Ashley (2008), the stall is not likely due to shortcomings in forecasting and/or the integrated warning system; rather, it may be due to the growing vulnerability caused by sociodemographic changes and, as illustrated previously herein and elsewhere (Ashley et al. 2014), the expanding bull's-eye effect.

As suggested, the tornado mortality rate found at the U.S. scale is not identical across the constituent space. For instance, the contemporary (1985-2014) mortality rate for the MS is more than 4-5 times greater than that found for the larger CD and U.S. areas. This difference in rates between the MS and the larger enumerations has been increasing; the MS mortality rates in the early (1880-1924) and middle (1925-84) parts of the record were 2-4 times greater than that found at the CD and U.S. scales. This rate of change difference may be partly due to the large population increase that has occurred in the MS since the 1980s, placing greater numbers of vulnerable people (Ashley 2007) in the path of tornadoes in this high-risk area (Coleman and Dixon 2014). Though not as elevated as the MS, the $\mathrm{CP}$ region has a contemporary mortality rate that is nearly 3.5 times that found at the national scale; moreover, when a least squares trend is fit to the modern data, the mortality rate has been increasing in this region. Uniquely, the MW region has a contemporary mortality rate that is below the U.S. and $\mathrm{CD}$ - and even $\mathrm{HP}$-rates, which is attributable to the relatively high 
population (i.e., 1.7-2 times the population found in the CP and MS) and the low number of fatalities in this region since 1985 (e.g., mean deaths of $6.7 \mathrm{yr}^{-1}$ in the MW compared to over $26 \mathrm{yr}^{-1}$ in the MS). Despite the relatively low death rate, the MW has the greatest regional increase in rates since bottoming out in the 1980s. These results reveal that the broader contextual hazard constituents of risk and exposure do manifest in the definitive hazard impact-human mortality.

Case studies. We have assessed the commingling of tornado risk and exposure at the conterminous and regional scales. Naturally, the question arises as to how these disaster constituents manifest at the scale of a tornado. We use a case study perspective on three infamous and well-documented tornadoes to explore this question. The cases examined include the MW's 28 August 1990 Oswego-Plainfield, Illinois, F5 (Fujita 1993; Hall and Ashley 2008); the MS's 27 April 2011 Tuscaloosa-Birmingham, Alabama, EF4 (Karstens et al. 2013; Knupp et al. 2014); and the CP's 20 May 2013 Newcastle-Moore EF5 (Atkins et al. 2014; Burgess et al. 2014). No HP case was applied due to the lack of recent violent events and/or detailed postevent surveys in the domain. While the events are disparate in their dimensional attributes (Table 2), we are most interested in how each case intersects the temporally evolving HU exposure surface. This assumes that there are no other vulnerability factors beyond HUs that influence disaster consequences, which, of course, is not true. However, the analysis provides a marker for evaluating changes in disaster potential over time, presenting a foundation for exploring additional vulnerability and mitigation dynamics in the future.

Of the three cases, the 2013 Newcastle-Moore tornado had the greatest relative change in HUs affected from 1950 to 2010, increasing by almost three orders of magnitude, or a percent change of over 8,000 ! Because of the finescale postevent analysis performed by researchers (Atkins et al. 2014), this particular event provides an instrument for evaluating how close the modeled HU cost surface employed in this research is to observed data. Atkins et al. (2014) state that the 2013 tornado impacted 4,531 total structures with $78 \%(3,534)$ of those structures categorized as "residential." Our assessment of the same tornado occurring in 2010 indicates 3,829 HUs affected, which is an $8 \%$ difference. Most of this slight difference may arise because of our use of the official NWS path $\left(23.6 \mathrm{~km}^{2}\right.$ vs Atkins et al.'s $\left.19.0 \mathrm{~km}^{2}\right)$ and HUs, rather than "residential structures," as a metric.

The greatest absolute HU magnitude change was with the Tuscaloosa-Birmingham tornado, which amplified from just over 1,500 units affected in 1950 to nearly 9,000 in 2010. While the percent change during the period is not as large as that found in the other two events, it does illustrate the importance of tornado footprint size on the degree of tornado impact: that is, the 2011 tornado was $123.1 \mathrm{~km}^{2}$, which is over 5 times the impact size of the Newcastle-Moore tornado and 8 times the footprint of the OswegoPlainfield case.

The amount of developed area in each tornado path has increased sizably since 1950. In the Newcastle-Moore case, the percent of the path area that is considered developed has enlarged from $17.4 \%$ in 1950 to $82.6 \%$ in 2010 . As was found at the larger scales, most of this footprint's development has been in exurban (from 5.8\% of the footprint area in 1950 to $61.8 \%$ in 2010) and suburban morphologies (from $0.0 \%$ in 1950 to $16.8 \%$ in 2010). Moore's unique geographical position between Norman (home to a large public university) and the urban core of Oklahoma City has contributed to the extreme growth. Comparatively, the Oswego-Plainfield event has had a lower, yet still notable, increase in development within its footprint-the percentage of this MW path that is considered developed has increased from $11.6 \%$ in 1950 to $57.4 \%$ in 2010. Oswego and Plainfield are both exurban communities of Chicago that have witnessed a boom in residential growth during the last two decades. This high rate of development despite the area's relatively long distance from Chicago's

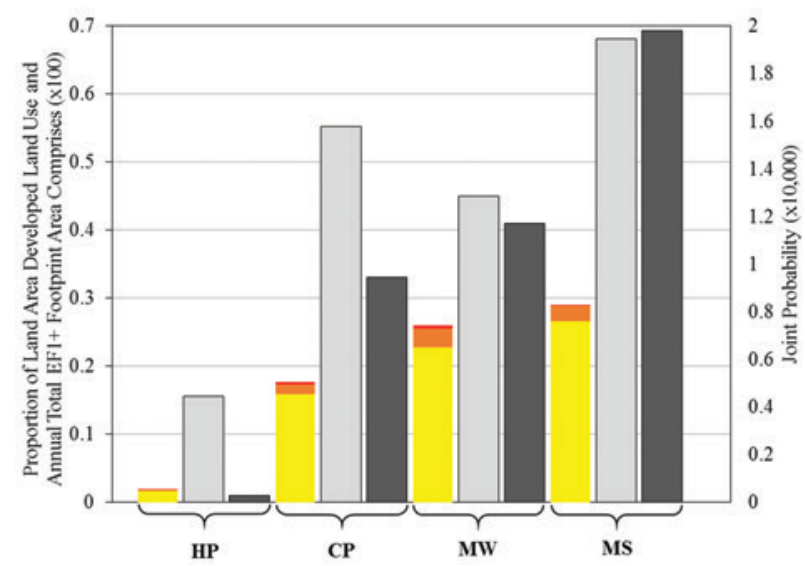

FIG. 12. The joint probability $(\times 10,000)$ that an EFI+ tornado path intersects a developed (urban, suburban, exurban) land-use grid cell in 2010. The left axis indicates the proportion $(\times 100)$ of regional land area that developed land use [exurban (yellow), suburban (orange), and urban (red)] and EFI+ annual total footprint (light gray) comprise. The right axis represents the joint probability $(\times 10,000)$ that an EFI+ tornado path traverses a developed grid cell (dark gray). 
core $(60 \mathrm{~km})$ and affiliated polycentric urban centers reveals how the expanding bull's-eye effect is rapidly advancing across the landscape. The sheer length of the Tuscaloosa-Birmingham tornado means that this event would invariably cross over large expanses of rural land. Even with this impact character, the tornado occurring in 2010 would have had a footprint made up of $42.5 \%$ developed land compared to $18 \%$ for the same event occurring in 1950. While these tornado cases have variability in footprint risk and exposure rates, the trends in residential impacts for each event reveal that the expanding bull's-eye effect is considerable even at the local scale.

CONCLUSIONS AND DISCUSSION. We have provided substantial evidence that escalating tornado impacts in the United States are driven fundamentally by growing built-environment exposure. The increasing tornado disaster potential is not uniform across the landscape (Fig. 12). For instance, the MS region has the greatest threat based on the juxtaposition of an immense tornado footprint risk and elevated exposure/development rates, which manifest in the area's high mortality rate. How these disaster constituents interact at the regional and local scales varies, but where they have increasing and greater overlap, the probability of disaster surges. Through the expanding bull's-eye effect, the acceleration of development will undoubtedly result in more frequent and higher impacts to the hazard.

Though research on how tornado risk may evolve in the future is in its infancy (Brooks 2013; Tippett et al. 2015), preliminary findings suggest that the threat may increase in some areas in the decades to come (Diffenbaugh et al. 2013; Gensini and Mote 2015). This potential enhancement in risk may collocate with areas most vulnerable to the hazard, resulting in even larger tornado disasters in the future than that expected due to societal vulnerabilities and affiliated changes alone. Alas, removing the broad climatological risk factor, it is important to remember that it only takes a single long-track, violent event transposed across a metropolitan area to create a disaster that is difficult to fathom (Wurman et al. 2007; Ashley et al. 2014; Rosencrants and Ashley 2015)

The findings herein and elsewhere have broader implications for all geophysical hazards and their resulting disasters. For instance, intensifying coastal development is creating a situation with more people and assets exposed to cyclone hazards and climate change threats, such as sea level rise (Pielke et al. 2008; Maloney and Preston 2014). In seismically and volcanically active areas, greater development is accelerating the potential for disaster (Strader et al. 2015b). The encroachment of the built-environment into wildland areas is increasing the likelihood of wildfire disasters (Bryant and Westerling 2014; Mann et al. 2014). Even the establishment of flood policies to restrict development within the 100 -yr floodplain has led to mixed results in reducing exposure within the unnatural, uncertain, and dynamic flood boundary while also having the unintended consequence of amplifying the development-and thus significantly increasing exposure-to the area immediately outside the 100-yr standard (Patterson and Doyle 2009). The hazard and geographic prospect list goes on and on, but the common theme is that growing impacts are primarily driven by escalating development and exposure. Though we did not assess components of social vulnerability (race, class, gender, etc.) or its complex spatiotemporal landscapes, we acknowledge that it can increase or attenuate hazard impacts (Cutter et al. 2009).

We have built a simple framework for tornado disaster attribution that can be improved upon by engaging changes in risk, vulnerability, and mitigation measures. All of these variables are extremely dynamic, difficult to measure at appropriate scales, and may vary, to some extent, on the hazard (Preston et al. 2011; Birkmann 2013). However, future research should try to assemble a more robust disaster attribution model by adding well-measured and vetted disaster components and mitigation factors, and doing so in a spatiotemporal framework (Huggel et al. 2013; Preston 2013; Birkmann et al. 2013). Information gleaned from these efforts will promote better policy, improve mitigation, and lead to a more resilient human and physical system in the face of inevitable hazards. Our framework did not "control" for builtenvironment development as in past research that has sought to uncover the potential role of anthropogenic climate change on disaster losses (cf. Bouwer 2011); rather, we were most interested in how that development was changing the disaster landscape.

Employing tornadoes as a discussion point, we have revealed that the changes in built-environment exposure magnitude and distribution are a major contributing factor to the weather disaster problem. Naturally, the question arises as to what to do about the issue and, certainly, this is a contentious and multifaceted problem to solve in the face of continued development that stretches across complex sociodemographic dimensions. Yet, there are both short- and long-term changes that could be implemented, from the individual homeowner level up to state and national scales, that must be addressed by policy makers and government agencies. 
For instance, the adoption, improvement, and enforcement of local, state, and regional land planning policies (removal of extremely vulnerable lands from development, employment of smart growth development strategy, etc.) will enhance community resilience by reducing the risk of impacts from tornadoes and other hazards (Godschalk et al. 1998; Burby et al. 2000; Pearce 2003; Mann et al. 2014; IPCC 2014). The enforcement or updating of building codes (e.g., requiring anchor bolts and hurricane ties on new residential development in wind hazard zones), investment in tornado safe rooms or shelters, changes in construction practices, and implementation of structural retrofits will lead to increased tornado survivability, reduced disaster costs, and greater individual, community, and institutional resilience (Merrell et al. 2002; Paton and Johnston 2006; Simmons and Sutter 2007; Prevatt et al. 2012; Simmons et al. 2015). As decision-makers, emergency managers, and land-use planners actively incorporate tornado disaster potential into their policies and strategies and, moreover, invest in those strategies, tornado hazard impacts can be reduced and potential disasters averted.

ACKNOWLEDGMENTS. We thank Dr. David Theobald (Conservation Science Partners) for the helpful discussion regarding the SERGoM. We also appreciate the feedback from Dr. Andrew Krmenec (NIU) and the fruitful discussions with Dr. Harold Brooks (NSSL). We are grateful to the three anonymous reviewers, whose suggestions significantly strengthened the manuscript.

\section{REFERENCES}

Abbey, R., Jr., and T. Fujita, 1975: Use of tornado path lengths and gradations of damage to assess tornado intensity probabilities. Preprints, Ninth Conf. on Severe and Local Storms, Norman, OK, Amer. Meteor. Soc., 286-293.

— ing tornado hazard probabilities: Refinements and theoretical considerations. Preprints, 11th Conf. on Severe Local Storms, Kansas City, MO, Amer. Meteor. Soc., 241-248.

Agee, E., and S. Childs, 2014: Adjustments in tornado counts, F-scale intensity, and path width for assessing significant tornado destruction. J. Appl. Meteor. Climatol., 53, 1494-1505, doi:10.1175/JAMC -D-13-0235.1.

Anderson, C. J., C. K. Wikle, Q. Zhou, and J. A. Royle, 2007: Population influences on tornado reports in the United States. Wea. Forecasting, 22, 571-579, doi:10.1175/WAF997.1.
Ashley, W.S., 2007: Spatial and temporal analysis of tornado fatalities in the United States: 1880-2005. Wea. Forecasting, 22, 1214-1228, doi:10.1175/2007WAF2007004.1.

—, A. J. Krmenec, and R. Schwantes, 2008: Vulnerability due to nocturnal tornadoes. Wea. Forecasting, 23, 795-807, doi:10.1175/2008WAF2222132.1.

_ S. Strader, T. Rosencrants, and A. J. Krmenec, 2014: Spatiotemporal changes in tornado hazard exposure: The case of the expanding bull's-eye effect in Chicago, Illinois. Wea. Climate Soc., 6, 175-193, doi:10.1175/WCAS-D-13-00047.1.

Atkins, N. T., K. M. Butler, K. R. Flynn, and R. M. Wakimoto, 2014: An integrated damage, visual, and radar analysis of the 2013 Moore, Oklahoma, EF5 tornado. Bull. Amer. Meteor. Soc., 95, 1549-1561, doi:10.1175/BAMS-D-14-00033.1.

Birkmann, J., 2013: Measuring Vulnerability to Natural Hazards: Towards Disaster Resilient Societies. 2nd ed. United Nations University Press, 720 pp.

— Opportunities and constraints in the context of climate change and disaster risk. Climatic Change, 133, 53-68, doi:10.1007/s10584-013-0913-2.

Boruff, B. J., J. A. Easoz, S. D. Jones, H. R. Landry, J. D. Mitchem, and S. L. Cutter, 2003: Tornado hazards in the United States. Climate Res., 24, 103-117, doi:10.3354/cr024103.

Bouwer, L. M., 2011: Have disaster losses increased due to anthropogenic climate change? Bull. Amer. Meteor. Soc., 92, 39-46, doi:10.1175/2010BAMS3092.1.

Brooks, H. E., 2004: On the relationship of tornado path length and width to intensity. Wea. Forecasting, 19, 310-319, doi:10.1175/1520-0434(2004)019<0310:OT ROTP $>2.0 . C O ; 2$.

— 2013: Severe thunderstorms and climate change. Atmos. Res., 123, 129-138, doi:10.1016/j .atmosres.2012.04.002.

— , and C. A. Doswell III, 2002: Deaths in the 3 May 1999 Oklahoma City tornado from a historical perspective. Wea. Forecasting, 17, 354-361, doi:10.1175/1520-0434(2002)017<0354:DITMOC $>2.0 . \mathrm{CO} ; 2$.

- - - and M. P. Kay, 2003: Climatological estimates of local daily tornado probability. Wea. Forecasting, 18, 626-640, doi:10.1175/1520 -0434(2003)018<0626:CEOLDT>2.0.CO;2.

— , G. W. Carbin, and P. T. Marsh, 2014: Increased variability of tornado occurrence in the United States. Science, 346, 349-352, doi:10.1126/science.1257460.

Brown, D. G., K. M. Johnson, T. R. Loveland, and D. M. Theobald, 2005: Rural land-use trends in the conterminous United States, 1950-2000. Ecol. Appl., 15, 1851-1863, doi:10.1890/03-5220. 
Bryant, B. P., and A. L. Westerling, 2014: Scenarios for future wildfire risk in California: Links between changing demography, land use, climate, and wildfire. Environmetrics, 25, 454-471, doi:10.1002/env.2280.

Burby, R. J., R. E. Deyle, D. R. Godschalk, and R. B. Olshansky, 2000: Creating hazard resilient communities through land-use planning. Nat. Hazards Rev., 1, 99-106, doi:10.1061/(ASCE)1527-6988(2000)1:2(99).

Burgess, D., and Coauthors, 2014: 20 May 2013 Moore, Oklahoma, tornado: Damage survey and analysis. Wea. Forecasting, 29, 1229-1237, doi:10.1175/WAF -D-14-00039.1.

Coleman, T. A., and P. G. Dixon, 2014: An objective analysis of tornado risk in the United States. Wea. Forecasting, 29, 366-376, doi:10.1175/WAF-D-13-00057.1.

Cutter, S. L., C. T. Emrich, J. J. Webb, and D. Morath, 2009: Social vulnerability to climate variability hazards: A review of the literature. Hazard Vulnerability Institute, Dept. of Geography, University of South Carolina, $44 \mathrm{pp}$.

Diffenbaugh, N. S., M. Scherer, and R. J. Trapp, 2013: Robust increases in severe thunderstorm environments in response to greenhouse forcing. Proc. Natl. Acad. Sci. USA, 110, 16361-16366, doi:10.1073 /pnas.1307758110.

Dixon, P. G., and A. E. Mercer, 2012: Reply to "Comments on 'Tornado risk analysis: Is Dixie Alley an extension of Tornado Alley?'” Bull. Amer. Meteor. Soc., 93, 408-410, doi:10.1175/BAMS-D-11-00219.1.

— $—$, J. Choi, and J. S. Allen, 2011: Tornado risk analysis: Is Dixie Alley an extension of Tornado Alley? Bull. Amer. Meteor. Soc., 92, 433-441, doi:10.1175/2010BAMS3102.1.

Doswell, C. A., III, 2007: Small sample size and data quality issues illustrated using tornado occurrence data. Electron. J. Severe Storms Meteor., 2 (5). [Available online at www.ejssm.org/ojs/index.php/ejssm /article/viewarticle/26/27.]

— , and D. W. Burgess, 1988: On some issues of United States tornado climatology. Mon. Wea. Rev., 116, 495-501, doi:10.1175/1520-0493(1988)116<0495:OS IOUS $>2.0 . \mathrm{CO} ; 2$.

— , A. R. Moller, and H. E. Brooks, 1999: Storm spotting and public awareness since the first tornado forecasts of 1948. Wea. Forecasting, 14, 544-557, doi:10.1175/1520 -0434(1999)014<0544:SSAPAS>2.0.CO;2.

— , H. E. Brooks, and N. Doztek, 2009: On the implementation of the enhanced Fujita scale in the USA. Atmos. Res., 93, 554-563, doi:10.1016/j .atmosres.2008.11.003.

— , G. W. Carbin, and H. E. Brooks, 2012: The tornadoes of spring 2011 in the USA: An historical perspective. Weather, 67, 88-94, doi:10.1002/wea.1902.
Elsner, J. B., S. C. Elsner, and T. H. Jagger, 2015: The increasing efficiency of tornado days in the United States. Climate Dyn., 45, 651-659, doi:10.1007 /s00382-014-2277-3.

Farney, T. J., and P. G. Dixon, 2015: Variability of tornado climatology across the continental United States. Int. J. Climatol., 35, 2993-3006, doi:10.1002/joc.4188.

Field, C. B., and Coauthors, Eds., 2012: Managing the Risks of Extreme Events and Disasters to Advance Climate Change Adaptation. Cambridge University Press, $582 \mathrm{pp}$.

Fujita, T. T., 1987: U.S. tornadoes: Part 1: 70-year statistics. SMRP Research Paper SMRP-RP-218, 133 pp.

— 1993: Plainfield tornado of August 28, 1990. The Tornado: Its Structure, Dynamics, Prediction and Hazards, Geophys. Monogr., Vol. 79, Amer. Geophys. Union, 1-17.

Gagan, J. P., A. Gerard, and J. Gordon, 2010: A historical and statistical comparison of "Tornado Alley" to “Dixie Alley.” Natl. Wea. Dig., 34 (2), 145-155.

Gensini, V. A., and W. S. Ashley, 2011: Climatology of potentially severe convective environments from North American Regional Reanalysis. Electron. J. Severe Storms Meteor., 6 (8). [Available online at www.ejssm .org/ojs/index.php/ejssm/article/viewArticle/85.]

— , and T. L. Mote, 2014: Estimations of hazardous convective weather in the United States using dynamical downscaling. J. Climate, 27, 6581-6589, doi:10.1175/JCLI-D-13-00777.1.

$\longrightarrow$, and — 2015: Downscaled estimates of late 21 st century severe weather from CCSM3. Climatic Change, 129, 307-321, doi:10.1007/s10584-014 $-1320-z$.

— C. A. Ramseyer, and T. L. Mote, 2014: Future convective environments using NARCCAP. Int. J. Climatol., 34, 1699-1705, doi:10.1002/joc.3769.

Godschalk, D., T. Beatley, P. Berke, D. Brower, and E. J. Kaiser, 1998: Natural Hazard Mitigation: Recasting Disaster Policy and Planning. Island Press, 591 pp.

Grazulis, T. P., 1993: Significant Tornadoes: 1680-1991. Environmental Films, 1326 pp.

Hall, S. G., and W. S. Ashley, 2008: The effects of urban sprawl on the vulnerability to a significant tornado impact in northeastern Illinois. Nat. Hazards Rev., 9, 209-219, doi:10.1061/(ASCE) 1527 -6988(2008)9:4(209).

Huggel, C., D. Stone, M. Auffhammer, and G. Hansen, 2013: Loss and damage attribution. Nat. Climate Change, 3, 694-696, doi:10.1038/nclimate1961.

IPCC, 2014: Climate Change 2014: Mitigation of Climate Change. Cambridge University Press, 1465 pp. [Available online at www.ipcc.ch/pdf/assessment-report /ar5/wg3/ipcc_wg3_ar5_full.pdf.] 
Karstens, C. D., W. A. Gallus Jr., B. D. Lee, and C. A. Finley, 2013: Analysis of tornado-induced tree fall using aerial photography from the Joplin, Missouri, and Tuscaloosa-Birmingham, Alabama, tornadoes of 2011. J. Appl. Meteor. Climatol., 52, 1049-1068, doi:10.1175/JAMC-D-12-0206.1.

Knupp, K. R., and Coauthors, 2014: Meteorological overview of the devastating 27 April 2011 tornado outbreak. Bull. Amer. Meteor. Soc., 95, 1041-1062, doi:10.1175/BAMS-D-11-00229.1.

Maloney, M. C., and B. L. Preston, 2014: A geospatial dataset for U.S. hurricane storm surge and sea-level rise vulnerability: Development and case study applications. Climate Risk Manage., 2, 26-41, doi:10.1016/j. crm.2014.02.004.

Mann, M. L., P. Berck, M. A. Moritz, E. Batllori, J. G. Baldwin, C. K. Gately, and D. R. Cameron, 2014: Modeling residential development in California from 2000 to 2050: Integrating wildfire risk, wildland and agricultural encroachment. Land Use Policy, 41, 438-452, doi:10.1016/j.landusepol.2014.06.020.

Marsh, P. T., and H. E. Brooks, 2012: Comments on "Tornado risk analysis: Is Dixie Alley an extension of Tornado Alley?” Bull. Amer. Meteor. Soc., 93, 405-407, doi:10.1175/BAMS-D-11-00200.1.

Merrell, D., K. M. Simmons, and D. Sutter, 2002: Taking shelter: Estimating the safety benefits of tornado safe rooms. Wea. Forecasting, 17, 619-625, doi:10.1175/1520 -0434(2002)017<0619:TSETSB>2.0.CO;2.

Mohleji, S., and R. Pielke Jr., 2014: Reconciliation of trends in global and regional economic losses from weather events: 1980-2008. Nat. Hazards Rev., 15, 04014009, doi:10.1061/(ASCE)NH.1527 $-6996.0000141$.

Morss, R., O. Wilhelmi, G. A. Meehl, and L. Dilling, 2011: Improving societal outcomes of extreme weather in a changing climate: An integrated perspective. Annu. Rev. Environ. Resour., 36, 1-25, doi:10.1146 /annurev-environ-060809-100145.

NCDC, 2015: Billion-dollar weather and climate disasters: Overview. [Available online at www.ncdc.noaa .gov/billions/.]

Paton, D., and D. Johnston, 2006: Disaster Resilience: An Integrated Approach. Thomas Books, 320 pp.

Patterson, L. A., and M. W. Doyle, 2009: Assessing effectiveness of national flood policy through spatiotemporal monitoring of socioeconomic exposure. J. Amer. Water Resour. Assoc., 45, 237-252, doi:10.1111/j.1752-1688.2008.00275.x.

Paul, B. K., 2011: Environmental Hazards: Contexts, Perspectives and Management. Wiley, $334 \mathrm{pp}$.

Pearce, L., 2003: Disaster management and community planning, and public participation: How to achieve sustainable hazard mitigation. Nat. Hazards, 28, 211-228, doi:10.1023/A:1022917721797.

Pielke, R. A., Jr., J. Gratz, C. W. Landsea, D. Collins, M. A. Saunders, and R. Musulin, 2008: Normalized hurricane damage in the United States: 1900-2005. Nat. Hazards Rev., 9, 29-42, doi:10.1061/(ASCE)1527 -6988(2008)9:1(29).

Preston, B. L., 2013: Local path dependence of U.S. socioeconomic exposure to climate extremes and the vulnerability commitment. Global Environ. Change, 23, 719-732, doi:10.1016/j.gloenvcha.2013.02.009.

_, E. J. Yuen, and R. M. Westaway, 2011: Putting vulnerability to climate change on the map: A review of approaches, benefits, and risks. Sustainability Sci., 6, 177-202, doi:10.1007/s11625-011-0129-1.

Prevatt, D., and Coauthors, 2012: Making the case for improved structural design: Tornado outbreaks of 2011. Leadership Manage. Eng., 12, 254-270, doi:10.1061/(ASCE)LM.1943-5630.0000192.

Ramsdell, J., Jr., J. Rishel, and A. Buslik, 2007: Tornado climatology of the contiguous United States. U.S. Nuclear Regulatory Commission Rep. NUREG/CR4461, Revision 2, PNNL-15112, Revision 1, 246 pp. [Available online at http://pbadupws.nrc.gov/docs /ML0708/ML070810400.pdf.]

Reinhold, T., and B. Ellingwood, 1982: Tornado damage risk assessment. U.S. Nuclear Regulatory Commission Rep. NUREG/CR-2944, 61 pp.

Rosencrants, T. D., and W. S. Ashley, 2015: Spatiotemporal analysis of tornado exposure in five U.S. metropolitan areas. Nat. Hazards, 78, 121-140, doi:10.1007 /s11069-015-1704-z.

Schaefer, J. T., D. L. Kelly, and R. F. Abbey, 1986: A minimum assumption tornado-hazard probability model. J. Climate Appl. Meteor., 25, 1934-1945, doi:10.1175/1520-0450(1986)025<1934:AMATHP $>2.0 . \mathrm{CO} ; 2$.

Shafer, C. M., and C. A. Doswell III, 2010: A multivariate index for ranking and classifying severe weather outbreaks. Electron. J. Severe Storms Meteor., 5 (1). [Available online at http://ejssm.org/ojs/index.php /ejssm/article/viewArticle/62.]

Simmons, K. M., and D. Sutter, 2007: Tornado shelters and the housing market. Constr. Manage. Econ., 25, 1119-1126, doi:10.1080/01446190701618299.

—, and _ 2011: The Economic and Societal Impact of Tornadoes. Amer. Meteor. Soc., 282 pp.

—_ —, and R. Pielke Jr., 2013: Normalized tornado damage in the United States: 1950-2011. Environ. Hazards, 12, 132-147, doi:10.1080/17477891.2012 .738642 .

— , P. Kovacs, and G. A. Kopp, 2015: Tornado damage mitigation: Benefit-cost analysis of enhanced 
building codes in Oklahoma. Wea. Climate Soc., 7, 169-178, doi:10.1175/WCAS-D-14-00032.1.

Smith, A., and J. Matthews, 2015: Quantifying uncertainty and variable sensitivity within the U.S. billion-dollar weather and climate disaster cost estimates. Nat. Hazards, 77, 1829-1851, doi:10.1007 /s11069-015-1678-x.

Smith, B. T., R. L. Thompson, J. S. Grams, C. Broyles, and H. E. Brooks, 2012: Convective modes for significant severe thunderstorms in the contiguous United States. Part I: Storm classification and climatology. Wea. Forecasting, 27, 1114-1135, doi:10.1175/WAF-D-11-00115.1.

Strader, S. M., W. Ashley, A. Irizarry, and S. Hall, 2015a: A climatology of tornado intensity assessments. Meteor. Appl., 22, 513-524, doi:10.1002/met.1482.

—_ _ - and J. Walker, 2015b: Changes in volcanic hazard exposure in the Northwest USA from 1940 to 2100. Nat. Hazards, 77, 1365-1392, doi:10.1007 /s11069-015-1658-1.

Theobald, D. M., 2005: Landscape patterns of exurban growth in the USA from 1980 to 2020. Ecol. Soc., 10 (1), 32. [Available online at www.ecologyandsociety .org/vol10/iss1/art32/.]

Tippett, M. K., 2014: Changing volatility of U.S. annual tornado reports. Geophys. Res. Lett., 41, 6956-6961, doi:10.1002/2014GL061347.

— , A. H. Sobel, and S. J. Camargo, 2012: Association of U.S. tornado occurrence with monthly environmental parameters. Geophys. Res. Lett., 39, L02801, doi:10.1029/2011GL050368.

— , J. T. Allen, V. A. Gensini, and H. E. Brooks, 2015: Climate and hazardous convective weather. Curr. Climate Change Rep., 1, 60-73, doi:10.1007/s40641 -015-0006-6.

Trapp, R. J., and H. E. Brooks, 2013: Regional characterization of tornado activity. J. Appl. Meteor. Climatol., 52, 654-659, doi:10.1175/JAMC-D-12-0173.1.
—, N. S. Diffenbaugh, H. E. Brooks, M. E. Baldwin, E. D. Robinson, and J. S. Pal, 2007a: Changes in severe thunderstorm environment frequency during the 21st century caused by anthropogenically enhanced global radiative forcing. Proc. Natl. Acad. Sci. USA, 104, 19719-19723, doi:10.1073/pnas.0705494104.

—, B. A. Halvorson, and N. S. Diffenbaugh, 2007b: Telescoping, multimodel approaches to evaluate extreme convective weather under future climates. J. Geophys. Res., 112, D20109, doi:10.1029/2006JD008345.

— E. D. Robinson, M. E. Baldwin, N. S. Diffenbaugh, and B. R. J. Schwedler, 2011: Regional climate of hazardous convective weather through high-resolution dynamical downscaling. Climate Dyn., 37, 677-688, doi:10.1007/s00382-010-0826-y.

U.S. Bureau of the Census, 2010: Housing units, 2010. Accessed 1 May 2015. [Available online at http:// quickfacts.census.gov/qfd/meta/long_HSG030210 .htm.]

Verbout, S. M., H. E. Brooks, L. M. Leslie, and D. M. Schultz, 2006: Evolution of the U.S. tornado database: 1954-2003. Wea. Forecasting, 21, 86-93, doi:10.1175 /WAF910.1.

Visser, H., A. C. Petersen, and W. Ligtvoet, 2014: On the relation between weather-related disaster impacts, vulnerability and climate change. Climatic Change, 125, 461-477, doi:10.1007/s10584-014-1179-z.

Widen, H. M., and Coauthors, 2013: Adjusted tornado probabilities. Electron. J. Severe Storms Meteor., 8 (7). [Available online at http://ejssm.org/ojs/index.php /ejssm/article/view/131.]

Wurman, J., C. Alexander, P. Robinson, and Y. Richardson, 2007: Low-level winds in tornadoes and potential catastrophic tornado impacts in urban areas. Bull. Amer. Meteor. Soc., 88, 31-46, doi:10.1175/BAMS-88-1-31. 